Social Epistemology

A Journal of Knowledge, Culture and Policy

\title{
Expertise, Relevance and Types of Knowledge
}

\section{Pierluigi Barrotta \& Eleonora Montuschi}

To cite this article: Pierluigi Barrotta \& Eleonora Montuschi (2018) Expertise, Relevance and Types of Knowledge, Social Epistemology, 32:6, 387-396, DOI: 10.1080/02691728.2018.1546345

To link to this article: https://doi.org/10.1080/02691728.2018.1546345

Published online: 29 Nov 2018.

Submit your article to this journal $\pi$

III Article views: 14

View Crossmark data $\asymp$ 


\title{
Expertise, Relevance and Types of Knowledge
}

\author{
Pierluigi Barrotta ${ }^{\mathrm{a}}$ and Eleonora Montuschi ${ }^{\mathrm{b}}$ \\ anniversity of Pisa; ${ }^{\text {b }} \mathrm{Ca}^{\prime}$ Foscari University of Venice
}

\begin{abstract}
In this paper, we argue that the formulation of typical expert judgements here referred to as 'judgement calls' - entails figuring out how to apply 'general knowledge' to specific circumstances (what we call the 'relevance query'). This requires wisdom, in its original Aristotelian sense, on the part of the scientific expert, as knowledge of laws and initial conditions is not sufficient to make judgement calls. Experts need to take into consideration factors coming from 'outside' the remit of scientific theory, thereby crossing the divide between empirical evidence and socio-political input (what we call the 'expert query'). Arguing against some form of the fact-value distinction is far from an original move, but we will do so both by avoiding the conclusion that expert judgements are nothing but political (against the received view in the sociology of science), and by advocating a somewhat novel perspective. We will claim that expert scientific knowledge proves to be inadequate when it is not integrated with local knowledge, which we define as the knowledge of all factors, which are deemed relevant to the application of general knowledge to specific circumstances. The possession and role of this type of knowledge, though partly an empirical (or sociologically situated) question, can be justified by epistemological reasons.
\end{abstract}

\section{KEYWORDS}

Ceteris paribus clauses; expert knowledge; judgement calls; general and local knowledge; relevance; types of explanation; wisdom

\section{Preliminaries}

It is a short step from arguing that there is no sharp divide between science and politics to arguing that so-called scientific experts do not have more truthful or objective knowledge of the world than ordinary people. This step - taken by some sociologists of science for example - is, we believe, unnecessarily radical or, indeed, too short. ${ }^{1}$ Instead, we claim that the old problem of epistemology (when is a belief warranted or rationally justified?) is indispensable to understand the role and nature of expert knowledge. As we will argue, a qualified epistemological analysis may well lead to rejecting the distinction between science and society (so welcomed by the sociologists of science), without going so far as to support the view that the content and purpose of science is nothing but political (an unnecessary and, for us at least, unwelcome radical outcome).

In this essay, we will address the following two related questions concerning expertise (hereafter the Expertise query):

- How does expert scientific knowledge prove sometimes inadequate as the sole adjudicator of what course of action to undertake?

- How do different types of knowledge, sometimes also 'non-expert', become necessary to formulate a judgement call (i.e. a judgement in view of action)? 
Contemporary sociology of science addresses this query in the way outlined above. We argue instead that this query could be considerably clarified, and perhaps better met, by finding an answer to the following typical question of knowledge transfer (hereafter, and for reasons that will be made explicit later, the Relevance query):

- How can general knowledge apply to specific circumstances?

To find an appropriate answer to this second query, we suggest making use of some tools from the philosophy of science. ${ }^{2}$

In this essay, we will proceed as follows. In the first section, we will start by addressing the Relevance query. In the following section, with the help of some real-life examples, we will show how a suitable understanding and formulation of the Relevance query could provide an answer to each of the two questions that constitute the Expertise query. A trait that such understanding brings to the fore is the crucial role played by local knowledge (in a meaning that will be specifically articulated) in formulating judgements of epistemic relevance. Acknowledging such a trait can, convincingly we believe, support an argument to the effect that both scientific experts and 'non-experts' can be considered knowledge carriers, and consequently also explain why both can and should combine or share information. ${ }^{3}$ In some concluding remarks, we will emphasise how this argument is by its own very nature epistemological. It is an argument that can indeed become instrumental in rejecting the divide between the scientific/technical sphere and the political/social sphere, though for reasons other than those advocated by the sociology of science, and with different consequences.

\section{The Relevance Query: General and Local Knowledge}

It has been known since Aristotle that applying a general rule or norm to particular circumstances requires a certain amount of wisdom. ${ }^{4}$ In Nicomachean Ethics wisdom is defined as an essential component of all practical judgements: 'Nor is wisdom,' Aristotle writes, 'only concerned with universals: to be wise, one must also be familiar with the particular, since wisdom has to do with action, and the sphere of action is constituted by particulars' (Aristotle 2002, 1141b15-17). Nonetheless, the awareness that this is also the case when we apply natural laws to particular cases can be hailed as an achievement of post-positivist philosophy of science. In order to see how Aristotle's problem is not so far removed from post-positivistic concerns, we need to take what at first sight might appear a little detour through the well-known and yet controversial terrain of the function of laws in explanatory and predictive contexts.

In their simplest neopositivist formulation, scientific laws are universal empirical generalizations which, together with a number of initial conditions, allow for the deduction of a description of some phenomena. 'Whenever a metallic bar is heated it increases in length,' together with 'object $a$ is a heated metal bar' will lead us to deduce that object $a$ (a metallic bar) will increase its length. ${ }^{5}$ Hempel expresses this in the following way:

The explanatory import of the whole argument lies in showing that the outcome described in the explanandum was to be expected in view of the antecedent circumstances and the general laws listed in the explanans. More precisely, the explanation may be constructed as an argument in which the explanandum is deduced from the explanans. (Hempel 1965, 299)

Therefore, following the nomological instruction, the description of specific events ('the bar will lengthen') is deduced from specific antecedent circumstances (this is a metal bar and it is heated). In a nutshell, general laws allow us to claim, via deductive inferences, that if the situation (i.e. initial or antecedent conditions) is $\mathrm{X}$, then $\mathrm{Y}$ will happen'.

All this is well known - as it is also that no laws, even the most successful ones, guarantee a plain, straightforward deduction of phenomena when applied to specific circumstances. Let us go back to our toy example of a scientific law: 'Whenever a metallic bar is heated it increases in 
length'. To comply with standard neopositivism, we would say that the truth of the law, together with the initial condition that a metallic bar has been actually heated, can alone provide sufficient conditions for the aforementioned outcome. And yet, it is easy to show why this claim is far from being correct. Suppose that a mischievous child hammers simultaneously the two extremities of the metallic bar while it is being heated. In this case, the bar will not show the property of increasing its length. Thus, we should conclude that (a) either the law or the initial condition is false, or (b) a deductive inference is not adequate to offer an explanation of the behaviour of the heated bar, since the truth of the conclusion does not necessarily follow from the truth of the premises. If we have reasons (and often there are good reasons) to rule out (a), we can only question the adequacy of (b).

It would be wrong to think that this problem comes down to claiming that even the hard sciences require a 'ceteris paribus' clause when natural laws are applied to particular circumstances (namely, a clause to the effect that, if nothing interferes, $x$ will be the case). It was the late Hempel who cast doubt on this apparently easy solution to the failures of deductivism. He pointed out that 'the idea of a ceteris paribus clause is itself vague and elusive' since it does not tell us 'what other things, and equal to what' (Hempel 1988, 156-7). By using a ceteris paribus clause, we cannot fix deductive failures when in the presence of mischievous children. As Hempel further writes:

A [ceteris paribus clause] as here understood is not a clause that can be attached to a theory as a whole and vouchsafe its deductive potency by asserting that in all particular situations to which the theory is applied, disturbing factors are absent. Rather [the ceteris paribus clause] has to be conceived as a clause which pertains to some particular application of the given theory and which asserts that in the case at hand, no effective factors are present other than those explicitly taken into account. (Ibid., p. 154, italics are ours) ${ }^{6}$

Therefore, to formulate a valid deductive argument we need to establish that in a given application of the theory all relevant factors have been taken into account. We cannot simply claim that, if no disturbing factors are present, then the truth of the theory warrants the deduction of the phenomenon. A deductive model of explanation is not hypothetical reasoning: it must explain why a phenomenon occurred 'in the case at hand'. So, the problem raised by Hempel against deductivism can quite simply be summarized as follows: ceteris paribus clauses 'transcend' the conceptual borderlines of a theory. After all, no scientific laws can take into account the lamentable fantasy of a child!

On a contemporary scene, and further away from neopositivism, another prominent philosopher of science came to a somewhat similar conclusion. Nancy Cartwright pictures the view of theories based on the deductive power of laws by using the analogy with a 'vending machine.' We can think of this type of theories as a machine being fed with some input (i.e. some prescribed forms/ principles/premises/etc.) with the view of expecting some desired output. The theory/machine gurgitates for a while, and eventually spits out the sought-for representation, 'plonk, on the tray, fully formed, as Athena was from the brain of Zeus' (Cartwright 1999, 184). Cartwright's primary concern regarding this way of representing theories specifically addresses the expectation of universalism. Even when theories are 'customised' to meet the special needs of the case at hand (e.g. by producing models that include improvements on the domain of applicability of the general theory), they do not contain in advance all the resources needed to represent all possible cases outside the remit of the domains where they work successfully. In her own words,

\footnotetext{
'our best and most powerful deductive sciences seem to support only a very limited kind of closure: so long as the only relevant factors at work are ones that can be appropriately modeled by the theory, the theory can produce exact and precise predictions. [...] But this is a long distance from hope that all situations lend themselves to exact and precise predictions."
}

This is why scientific laws must all be formulated with an at least implicit ceteris paribus clause a strong reminder against universalism, but also against the mechanical application of theory to particular cases. 'Producing a model of a new phenomenon like superconductivity is an incredibly difficult and creative activity.' (Ibid. 184). It requires wisdom too, we can add, in the Aristotelian 
sense mentioned above. Creativity and wisdom are not something we associate with vending machines. Theories, and the scientific laws they are built on, require to be 'fitted out' (Ibid. 39) on different concrete occasions, and to achieve this 'fitting out' we need to establish what relevant factors make them applicable to the occasion under scrutiny.

This means at least two things. First, what we have just called 'occasion' is not the same as a 'particular' that can be mechanically deduced from a premise plus initial conditions, so the 'fitting out' is not a task well-suited to a covering law. Secondly, the particular cases that a theory is meant to handle often, or at least in principle, go beyond the predictive power inscribed in its laws. Together, these two aspects bring us to the recognition that theoretical or nomological applicability is a 'bottom up' relationship, consolidated by a series of facts, and by the contribution of types of understanding, that are not necessarily included in the theory or laws whose applicability is ultimately at stake. We call the understanding of the facts that allow for an applicability relationship, to avoid confusion with some of the terminology of the received view, local knowledge.

To anticipate the argument that comes next, scientific experts need to be Aristotelically 'wise' when applying their general knowledge (laws and theories) to local circumstances. It is not sufficient for them to have good and well-established general knowledge. They also need local knowledge, namely the knowledge of the specific relevant circumstances to which general knowledge is applied. To reiterate, applicability requires a great deal of wisdom on the part of the expert, because affirming that all relevant factors have been thoroughly identified and included transcends the experts' 'machinery' (theories and laws).

So, local knowledge plays to some extent a different role from a ceteris paribus clause. It is not knowledge of facts to be kept at bay (so that a law is considered to be applicable to the domain identified by the hypothetical exclusion of all disturbing factors) but, more positively, knowledge of facts that speaks for relevance (so that a law or a theory proves its applicability 'bottom up'). Local knowledge is also different from knowledge of particulars, as in the received view. It is not knowledge that can be deduced from the premises of an explanatory/nomological argument. It is knowledge that transcends deduction, and possibly comes from 'other sources'.

\section{The Role and Value of Local Knowledge: An Epistemic Answer to the Expert Query}

Having addressed the Relevance query, how can we argue that it helps us in clarifying, and purportedly finding an answer to, the Expert query?

Let us remind ourselves what the two-pronged Expert query consists of:

- How does expert scientific knowledge sometimes prove inadequate as the sole adjudicator of what course of action to undertake?

- How do different types of knowledge, sometimes also 'non-expert', become necessary to formulate a judgement call (i.e. a judgement in view of action)?

Let's first reformulate the substance of the two questions in the terminology articulated by means of the Relevance query. As to the first prong, often experts rely only, or predominantly, on what we have previously called 'general knowledge,' incorrectly assuming that this knowledge is sufficient and adequate to guarantee a 'vending machine' result. As to the second prong, in disputes that involve scientific experts, knowledge provided from outside the domain of the expert often helps in adjusting their expertise to 'the case at hand.' In other words, using the terminology previously introduced, 'local knowledge' comes from 'other sources'. These 'other sources' are not necessarily included in the 'vending machine' input (and this is why they are sometimes looked upon with suspicion), but might prove useful (namely, relevant) in deciding 'what to do' in the circumstances. ${ }^{8}$ 
Leaving aside for the moment how the different sources of knowledge are to be combined to form a discerning, reliable judgement call, let us focus on the two questions just reformulated, and analyse them with the help of some concrete illustrations.

Our first example goes back to 1960s Italy, to what is known (and tragically remembered by earlier generations) as the 'Vajont disaster'. ${ }^{9}$ As a consequence of having built the tallest (at the time) arch dam in the world in an area where the fragility of the surrounding rocks was overlooked, and worrying premonitory signs of imminent catastrophe ignored, an entire town was completely wiped away by a gigantic wave of water (with peaks over $200 \mathrm{~m}$ ) overflowing the dam. The overflow was due to a massive landslide ( 260 million cubic metres over an area of $2 \mathrm{sq} . \mathrm{km}$ ) falling into the reservoir and, concomitantly, to the dam resisting the impact of the slide, causing the water to fill an entire valley in a matter of seconds.

How could things go so wrong? How could the several warnings of danger, well known and repeatedly reported by the local community, well before the disaster, be overlooked? How could the Adriatic Energy Corporation SADE, ${ }^{10}$ the company in charge of the project, not take the risk of disaster more seriously? How could Carlo Semenza, the engineer who designed and chose the location for the dam, act so recklessly? These are some of the questions that haunted public opinion, the media and the Italian political scene for years to come after the disaster.

It is important to note that studies on the structural stability of the valley had been carried out in advance of building the dam, but they were confined to the abutment area and its hydraulic properties (the only studies, it must be noted, required by law in those days). Nowadays it may seem foolhardy to embark on a work of such magnitude without a preliminary and in-depth study of the inner constitution and resistance of the slopes in the valley. Yet at the time, the formidable engineering challenges of the project took precedence over the geological uncertainties of the natural environment.

This choice was partly justified by the aforementioned lack of juridical norms, and partly by the existence of well-supported knowledge of the nature and behaviour of the rocks typical of that area (cf. Semenza 2005, 32 ff.; Carloni 1995, 13ff.). 'From a geological point of view - Carlo Semenza wrote - the rocks [of the Veneto region] are generally very good [...]. Overall, limestone is honest because it reveals its flaws on its surface' (cited in Gervasoni 1968, 11). In-depth geological studies were therefore considered unnecessary because the typical rocks of the area did not raise any visible concern. The focus was: how to build a good dam, rather than: how to guarantee that the surrounding natural environment would not interfere with the project. However, this was a fatal mistake. Relying on general geological understanding of the behaviour of limestone was insufficient and inadequate, for reasons akin to those pointed out by the Relevance Query as addressed in the previous section. Let's see why.

No doubt, in order to pursue a project of such magnitude as the Vajont arch dam, the community of experts needed sophisticated general knowledge about, for instance: the chemical and physical characteristics of the rocks forming the terrestrial crust; the geological characteristics of landslides and their behaviour (in particular, their compactness and fall speed); and technological/hydraulic knowledge concerning the resistance of dams to water pressure. Semenza and his fellow scientists had all or most of this well-established knowledge. However, at the same time, some independent knowledge (not as well established) of facts regarding the specific surroundings where the dam was being built had been gradually emerging: deep fractures, tremors and loud noises coming from Mount Toc (the mountain behind the dam), a 50 million cubic meter slide in a nearby artificial lake that killed one man, and mounting evidence that a much bigger, much older landslide could have set itself in motion at any time. What Semenza failed to see was that (and how) this latter knowledge could and would have contributed to demonstrate the real worth of well established general knowledge (proof of effectiveness) in the particular circumstances where it was called upon. ${ }^{11}$

Possessing general chemical, physical, geological knowledge did not ipso facto entail relevant information about the impact of a specific environment on the rocks in question, and about the 
particular reaction of these particular rocks to that impact (i.e. a potential non-linear behaviour of limestone in the circumstances). In a word, the first thing that was missing from Carlo Semenza's choice of action was awareness of the role of local knowledge. This is because Semenza intuitively relied on a view of general knowledge to be fed into theories like vending machines (in the sense outlined in the previous section). In other words, the reasoning: 'if the situation is $\mathrm{X}$, theory $\mathrm{T}$ will tell us that $Y$ happens', applied to the case of the Vajont, becomes: 'if the rock in the Vajont is limestone (situation $\mathrm{X}$ ), and the theories in our background knowledge about this rock tell us $\mathrm{x}, \mathrm{y}, \mathrm{z}$ about limestone, then this very rock will behave in the way predicted by our background knowledge ( $Y$ will happen)'. By reasoning this way Semenza overlooked the problem (epistemological) of how to make general background knowledge 'relevant' to the specific context he was dealing with. In other words, he overlooked the role that local facts play in informing the application of general knowledge to specific circumstances.

Part of the reason for this neglect, we must now explain, is that some of this local knowledge was held by local people (the inhabitants of the valley, peasants and mountaineers in the Vajont). This knowledge was not 'scientific', it was not formalized in a textbook, nor was it discovered by scientific method and expressed in sophisticated geological classifications. Nonetheless, it could count as knowledge. In fact, the mountaineers' system of beliefs was warranted by a secular and detailed acquaintance with the slopes of the valley. However, at least partly because it was a type of knowledge formulated in such a way that did not command assent and credibility, the overall role of local knowledge in building relevance to 'the case at hand' was by and large overlooked. This was a mistake. As the Relevance query teaches us, applying the general to the particular is not an automatic, deductive trick played by theories - even the best-established among them.

The contested acknowledgement of the role of local knowledge in framing expert judgements emerges from the analysis of another case study, where what is at stake is the formulation of policy predictions. We move from twentieth century Italy to contemporary United Kingdom, where an ongoing dispute is taking place on whether culling badgers is the best measure to contain the spread of bovine tuberculosis. ${ }^{12}$ Scientific experts (different groups of scientists/advisors to the UK government since the 1970s) have long established that badgers are a significant cause of the spread of the disease (a ten-year 'Randomised Badger Control Trial' set the level of statistical significance at $40 \%$ in certain areas of the Southeast of Great Britain). Yet, scientists disagree on the measures to recommend in order to reduce the spread. The reason for disagreement is interesting because once more it involves the crucial issue raised by the Relevance Query. If we compare the two major scientific reports on the scientific evidence in the badger story (Bourne et al., 2007; King et al., 2007) we immediately realize why.

To the question 'would culling badgers efficiently slow down the progress of TB in cattle?' the Bourne et al. report gives a negative answer. The evidence presented in this report is not only based on the well-established findings of the RBCT. Given the complex nature of the problem, we are told, evidence should be combined from different sources (Bourne et al. 2007: 32): besides a firm grounding in genetic, epidemiological, ecological and environmental studies, also input from economic, social, practical (such as the technologies of disease management) and animal welfare arguments (partly also receptive of people's dispositions towards valuing the preservation of the countryside) are deemed critical in assessing the effectiveness of culling as a measure of TB control. To the same question, the King et al. report gives a positive answer, based entirely on the results of the RBCT. Here it is explicitly argued that the answer to the question above was formulated by focusing exclusively on the scientific basis (King et al. 2007, 3) and - following government brief by separating out 'economic or other practical issues. ${ }^{13}$

However, we can ask, could such issues easily be kept at bay? Could they be severed from a policy prediction formulated on the basis of scientific evidence? Do they just belong in the realm of 'practicalities'? We are somehow back to the problem posed earlier by the ceteris paribus clause. To see why let us first reformulate the type of reasoning from which the divide between Bourne and King supposedly takes shape.

The reasoning reads as follows: 
Given that $X$ (badgers) are a significant cause of infection, then $Y$ (culling badgers) might help contain the spread of the disease - provided that $x, y, z$ won't impede effective culling (ceteris paribus clause).

For King the proviso can be set aside in the argument for the credibility of the link between $X$ and $Y$ (from cause to prediction). In the Bourne et al. scenario, instead, the facts or factors included in the proviso are precisely what allows for the transition from $X$ to $Y$ : they are relevant to make $Y$ follow from $X$. Or, to use our earlier terminology, the knowledge of the facts included in the proviso should not so much help us keep certain facts at bay, but rather increase the acceptability of expert judgement - that is, in this case, correctly predicting a particular causal link. Predicting the effectiveness and sustainability of culling badgers by the farming industry is indeed a matter of judgement, besides being a matter of science. ${ }^{14}$ What enters this judgement is a whole range of practical questions that includes economic considerations, the feasibility of certain technologies of management, the practical implementation of certain courses of action, as well as values, ideologies, and common sense views. ${ }^{15}$ The costs of eradication programmes versus available resources vs. benefits in terms of some public interest, cattle's welfare against badgers' protection, the impact on the farming community and their rights vs. animal rights groups fighting for animals' interests (be they badgers or cows): these different types of information cannot be simplistically blanketed under the term 'practicalities'.

N. Cartwright uses the expression 'supportive factors' to refer to that variegated team of local conditions that in specific circumstances help us achieve applicability of general knowledge (Cartwright and Hardie 2012, 25). For example, in the case we are discussing, if we intend to ensure effective shooting of badgers a minimum distance from badger setts should be respected. However, what counts as 'minimum distance' depends on individual sets of badgers, and on badger activity within different sets, etc. Even when measurable effective shooting in one or more setts is achieved, this does not secure an overall result in terms of effective containment of the disease, since yet other factors might (and do normally) enter the picture to upset the expected general outcome. Finally, it goes without saying that for those who deny the appropriateness of shooting badgers altogether (e.g. on ethical grounds, or on general environmental predilections) different local factors will enter the domain of pertinent local knowledge - which further demonstrates how the appreciation of local knowledge goes well beyond what an ideal manual for the good use of scientific knowledge can predict and lead us to expect.

Both our examples offer, we believe, an appropriate illustration of how to answer the Expertise query sketched at the beginning of this section by making use of the role we established for local knowledge via the Relevance query. First, expert scientific knowledge is not sufficient to adjudicate predictively the consequences of adopting that knowledge in contexts of use. Both in the Vajont and the badger cases the role of local knowledge is crucial in securing a correct - more specifically, 'relevant' - use of expert knowledge in practical circumstances. Good scientific knowledge of the behaviour of limestone, and even more so, knowledge of the behaviour of badgers, needs to be situated in contexts relevant to what that knowledge is asked to support, or adjudicate. Secondly, adjusting expertise to 'the case at hand' requires knowledge provided from outside the strict domain of scientific expertise. Knowledge made available by different types of local communities (the inhabitants of the Vajont valley, animalist groups, farmers' supporters, public opinion) should not be dismissed hastily just because it has been formulated in terms other than those acknowledged by scientific discourse and methodology. Complex social disputes require the contribution of different stakeholders, for reasons that are not only political or sociological. We believe that addressing the Relevance query helps to identify the underlying epistemological reasons that support and justify the requirement of joint contribution, while prompting the creation of conditions for making collaborative exchange of knowledge happen in practice. To this we will turn in some concluding remarks. 


\section{Conclusions}

Scientific experts must be wise. No doubt, they must have thorough expertise grounded on the most reliable general knowledge. However, when applying general knowledge to specific circumstances, on concrete occasions, they also need knowledge of all factors that are deemed to be relevant to those occasions. As we have argued, general knowledge alone does not allow for the prediction and explanation of phenomena. Accordingly, the expert must go beyond general knowledge to make appropriate judgement calls, that is those judgements, which provide ground for action. It is not just a matter of well-established 'initial conditions' (i.e. in the terminology of the deductivist models of explanation, it is not sufficient for the antecedents of a theory or law to be true in the given circumstances). The expert also needs to take into consideration factors coming from 'outside' the remit of a theory, namely all those types of factors that are not included in the laws and initial conditions, and which are still relevant to the application of general knowledge to concrete occasions. This is where wisdom comes to the fore. As Aristotle noticed, knowledge of general rules (i.e. in the field of science, theories and laws) is different from the knowledge of their application to specific cases. The application moment is not and cannot be governed by other general rules. The application moment is a matter of judgement on the part of the expert.

In our analysis of the Relevance query we called the knowledge of the type of factors just mentioned local knowledge. The concept and role of local knowledge as emerged from our discussion of the Relevance query allowed us to formulate an answer to the two issues raised by the Expert query. More specifically, local knowledge provides us with an answer to the first prong of the Expert Query ("How does expert scientific knowledge sometimes prove inadequate as the sole adjudicator of what course of action to undertake?) in the following, simple terms: expert scientific knowledge proves to be inadequate when scientific knowledge is equated to general knowledge and is not integrated with local knowledge.

Local knowledge also provides an answer to the second prong of the Expert Query ('How do different types of knowledge, sometimes also "non-expert", become necessary to formulate a judgement call?'), though in a slightly more elaborate form. More is needed here than a logical or conceptual analysis. Nothing in principle prevents the experts from acquiring local knowledge, and if they acquired it, they would not need 'non-expert' knowledge. This is where conceptual analysis takes an empirical connotation. There are cases, such as in the badger story, where so-called 'practicalities' can, in a more or less direct way, make it to the list of factors included by the experts (as in Bourne et al. in analysis of evidence). There are other cases, such as the Vajont, where such inclusion proves more difficult. These are cases where local knowledge is not of a kind that is recognized by official science (it is provided by laypeople), though being endowed with highly specialized expertise. ${ }^{16}$ Ultimately, both examples make us reflect on a further but central aspect.

Relevance judgements are related to the social and moral values upheld by laypeople, and to the interests and wellbeing of different stakeholders. This further shows why, when making a judgement call, the expert acts in a context that goes well beyond the mere application of general knowledge. So, our overall answer to the Expert query from the perspective raised by the Relevance query takes the following form: general knowledge can apply to specific circumstances when experts possess local knowledge, namely the knowledge of all factors which are relevant to the application of general knowledge to specific circumstances. The possession of this knowledge, though partly an empirical question, is informed by epistemological reasons.

One final point brings us back to the comment made right at the beginning of this essay. By addressing the Expert query from within the framework of the Relevance query, we have singled out what we take to be pertinent epistemological reasons for overcoming the divide between the technical/scientific sphere and the social/political sphere without, at the same time, renouncing a qualified concept of expertise. We have indeed shown that such a divide does not hold, since 
local knowledge coming from 'other sources' (e.g. society) is often necessary to fill the gap between experts' knowledge and correct judgement calls. Notwithstanding this result, and contrary to much contemporary sociology of science, this does not lead us to delegitimize the very concept of scientific expertise.

\section{Notes}

1. It is interesting to note that even some sociologists of science have begun to distance themselves from the corrosive scepticism of much sociology of science, which tends to delegitimize the very notion of scientific expert. See for instance Collins and Evans (2002, 2017). However, Collins and Evans continue to support the irrelevance of epistemological studies - a view from which we differ.

2. Obviously, we do not purport to make a 'neutral' use of philosophy-of-science tools. These will be inevitably adapted to carry out the analysis of the queries we focus on in this article. Furthermore, we will avoid any excessive use of technical/analytic details. The task we set ourselves here is to bring in enough reasoned evidence to show that epistemology is not as 'boring' (read 'useless') as Bruno Latour repeatedly argued (see, for instance, Latour 2005). Nothing in the following denies the importance of sociological categories when reflecting on of the role and function of experts in societies. Equally, we believe that epistemological categories provide for relevant and specific tools of analysis.

3. The idea hinted at by this type of cooperation (i.e. the institution of a single community of inquirers) is developed more in detail in Barrotta (2018).

4. Cf. Aristotle (2002) 1104a5-10, p. 112: 'But if one says universally it is like this, what one says about particulars is even more lacking in precision; for it does not fall either under any expertise or under any set of rules - the agents themselves have to consider the circumstances relating to the occasion, just as happens in the cases of medicine, too, and of navigation'.

5. We here stick by a deliberately simplified picture. We do not distinguish between causal and coexistence laws. We do not mention the material condition for proper explanation. We do not bring in the controversial "correspondence rules', which connect theoretical terms with an observational language. Though important, none of these issues is directly relevant to the problem we are trying to articulate.

6. Hempel's view raised wide discussion. See, for instance, Coffa (1973), Giere (1988), Lange (1993), Lipton (1999), Pietrowski and Rey (1995), Schiffer (1991).

7. Cartwright (1999), p.188.

8. It might here be appropriate to reiterate the thrust of our argument: local knowledge, in the sense specified in this paper, becomes essential as soon as scientific results - as established by laboratory science - are transferred outside the laboratory and applied over and beyond the strictly controlled environment of the laboratory itself. As argued above, we are interested in the role of ceteris paribus clauses 1) in so much as the local factors they bring to bear on the applicability of general knowledge 'transcend' the realm of what a theory, a law, or an experiment are able to point at, and 2) as long as they prove to be factors not to be kept at bay, but rather to be included in what counts (in some circumstances) as relevant knowledge. We thank an anonymous referee for raising the question about local knowledge and laboratory science.

9. For a more detailed historical reconstruction, see Barrotta and Montuschi (2018).

10. This is the acronym from the Italian name of the corporation, i.e. 'Società Adriatica di Elettricità'.

11. Better, Semenza only started considering the relationship between the two types of knowledge too late, and the very connection was not approached with the attention and competence it deserved.

12. For a more detailed reconstruction of this case study see Montuschi (2017).

13. As for example emphasized in Environment, Food and Rural Affairs Committee, v. 2, 2008, p. 101.

14. We are echoing here a 2011 government policy document on the badger question, where we read that effectiveness of culling is to be considered 'a matter of judgement, not of science' (Defra 2011, 11).

15. For example it has been pointed out how in the dispute over badgers different images of, and feelings for, these animals play a rather important role in the way issues are framed by opposite sides. The image of a 'rogue badger' portrays a bad, deviant and antisocial creature, 'senile and virtually toothless (...), whose actions could be presented as a basis for intervention against a cherished animal' (Grant 2009). This image is in striking contrast with the sympathetic, favorable image adopted instead by animal protection groups, or by a large part of public opinion. See on this Montuschi $(2017,73)$.

16. This is why we have always been careful to use inverted commas when referring to 'non-experts'.

\section{Disclosure statement}

No potential conflict of interest was reported by the authors. 


\section{Notes on contributors}

Pierluigi Barrotta is full professor of Philosophy of science and the Head of the Department of Civilizations and Forms of Knowledge at the University of Pisa. He is currently carrying out research on the relationships between science and democracy and the role of scientific experts in society. He has recently published Scientists, Democracy and Society: A Community of Inquireres, Springer, New York 2018; and along with Giovanni Scarafile he edited Science and Democracy. Controversies and Conflicts, Benjamins, Amsterdam 2018.

Eleonora Montuschi is associate professor in Philosophy of Science in the Department of Philosophy and Cultural Heritage at the University Ca' Foscari of Venice. She is also senior research fellow and project leader at the Centre for Philosophy of Natural and Social Science at the London School of Economics and Political Science. Her research interests include objectivity (scientific and social), the theory and practice of evidence, and epistemological and methodological issues in the philosophy of expertise.

\section{References}

Aristotle. 2002. Nicomachean Ethics. translation by Christopher Rowe. Oxford: Oxford University Press. Barrotta, P. 2018. Scientists, Democracy and Society: A Community of Inquirers. New York, NY: Springer.

Barrotta, P., and E. Montuschi. 2018. "The Dam Project: Who are the Experts? A Philosophical Lesson from the Vajont Disaster." In Science and Democracy. Controversies and Conflicts, edited by P. Barrotta and G. Scarafile, 17-33. Amsterdam: Benjamins.

Bourne, J., et al. 2007. Bovine TB: The Scientific Evidence', Final Report of the Independent Scientific Group. London: Defra. June.

Carloni, G. C. 1995. Il Vajont trent'anni dopo. Esperienza di un geologo. Bologna: Clueb.

Cartwright, N. 1999. The Dappled World. A Study of the Boundaries of Science. Cambridge: Cambridge University Press.

Cartwright, N., and J. Hardie. 2012. Evidence-Based Policy, A Practical Guide to Doing It Better. New York, NY: Oxford University Press.

Coffa, J. A. 1973. Foundations of Inductive Explanations. Ph.D. Diss., University of Pittsburgh.

Collins, H., and R. Evans. 2002. "The Third Wave of Science Studies: Studies of Expertise and Experience." Reprinted in Selinger and Crease 2006: 39-110.

Collins, H., and R. Evans. 2017. Why Democracies Need Science. Cambridge: Polity Press.

Environment, Food and Rural Affairs Committee. 2008. "Badgers and Cattle TB: The Final Report of the Independent Scientific Group on Cattle TB. Fourth Report of Session 2007-2008", v. 2. House of Common. London: Stationary Office .

Gervasoni, A. 1968. II Vajont e le responsabilità dei manager. Milan: Bramante editrice.

Giere, R. N. 1988. "Laws, Theories, and Generalizations." In The Limitations of Deductivism, edited by A. Grümbaum and W. C. Salmon. Berkeley and Los Angeles: University of California Press.

Grant, W. 2009. "Intractable Policy Failure: The Case of Bovine TB and Badgers." The British Journal of Politics and International Relations 11. doi:10.1111/j.1467-856X.2009.00387.x.

Hempel, C. 1965. Aspects of Scientific Explanations and Other Essays in the Philosophy of Science. New York, NY: Free Press.

Hempel, C. 1988. "Provisoes: A Problem Concerning the Inferential Function of Scientific Theories." Erkenntnis 28 (2): 147-164. doi:10.1007/BF00166441.

King, D., et al. 2007. Bovine Tuberculosis in Cattle and Badgers. London: Defra. July.

Lange, M. 1993. "Natural Laws and the Problem of Provisoes." Erkenntnis 38: 233-248. doi:10.1007/BF01128982.

Latour, B. 2005. Un monde pluriel mais commun. Entretiens avec F. Ewald, La Tour d'Aigues: Édition de l'Aube.

Lipton, P. 1999. "All Else Being Equal." Philosophy 74: 155-168. doi:10.1017/S0031819199000236.

Montuschi, E. 2017. "Using Science, Making Policy." European Journal for the Philosophy of Science 7: 57-78. doi:10.1007/s13194-016-0143-3.

Pietrowki, P., and G. Rey. 1995. "When Other Things are Equal: Saving Ceteris Paribus Laws from Vacuity." British Journal for the Philosophy of Science 46: 81-110. doi:10.1093/bjps/46.1.81.

Schiffer, S. 1991. "Ceteris Paribus." Mind 100: 1-18. doi:10.1093/mind/C.397.1.

Semenza, E. 2005. La storia del Vaiont raccontata dal geologo che ha scoperto la frana. 1st. 2001, Ferrara: K-flah Editore. 